elementary physics. It is impossible to regard as rational understanding a mental condition involving simultaneous acceptance of directly contradictory ideas. Yet this is what is exhibited by very many of our university science entrants, and also by some of those who write the sixthform textbooks. Thus a student may be shown by a simple test to be acquainted with a particular concept, but it may well be that his ideas are so confused that the concept is useless to him.

$$
\begin{aligned}
& \text { Yours faithfully, } \\
& \text { J. W. WARREN }
\end{aligned}
$$

Department of Physics,

Brunel University,

London W3.

\section{The Future of Botany}

Sir,-We have recently gone through the process of appointing a lecturer to this department. In advertising the post, we made clear that although we were interested in candidates from a broad field there were certain specific requirements, possibly somewhat out of the ordinary. We had a number of applicants for the post and were very surprised to find that a good majority of these made no effort to indicate how they might fit in with our requirements. Furthermore, a good number of the candidates who were either just finishing, or had just finished, their PhD work seemed to think that their only mission in life was to further their postgraduate research and seemed in no way interested or anxious to broaden their interest in botany.

We found this all very disturbing and indeed it seems to us to echo some of the problems which have been discussed about the training of biologists in this country, particularly those made by the Royal Society Committee on Postgraduate Training in Biology and in the Swann Report. The feeling is that the training of PhDs in biological subjects is leading far too frequently to an inflexibility of outlook and a narrow-mindedness which is inherently bad for the progress of the subject.

The situation is becoming critical. Something needs to be done to discourage departments, and those within them who are responsible for training postgraduate students, from allowing these students to have their interests focused on very specialized problems to the neglect of their general biological education. Specialization of work may be a necessary part of achieving a proper scientific training, but if it leads to a narrow outlook then it is very bad training.

$$
\begin{aligned}
& \text { Yours faithfully, } \\
& \text { D. H. JENNINGs }
\end{aligned}
$$

Department of Botany,

University of Liverpool.

\section{Simplified Notation for Peptides in Computer Com- patible Format}

SIR,--Without wishing to comment one way or another on the proposals advanced by Revesz ${ }^{1}$, it should be pointed out that the IUPAC-IUB tentative rules $A$ One-Letter Notation for Amino Acid Sequences ${ }^{2}$ do not contain the letters $\mathrm{J}, \mathrm{O}, \mathrm{U}$ (which she allocates to the also not included Cit, Orn, CyS-SCy) and allocates $\mathrm{X}$ to "unknown or other", and not to HyPro. These differences from the IUPAC-IUB tentative rules are presented as if they were part of the latter, in which respect the article is misleading.

$$
\text { Yours faithfully, }
$$

\section{O. HOFFMANN-OSTENHOF}

IUPAC-IUB Combined Commission

on Biochemical Nomenclature.

- Revesz, G. S., Nature, 219, 1113 (1968).

$\because$ Arch. Biochem. Biophys., 125 (3), i (1968); Biochemistry, 7, 2703 (1968); Biochim. Biophys. Acta, 168, 6 (1968); Europ. J. Biochem., 5, 151 (1968); J. Biol. Chem., 243, 3551 (1968).
SIR,-- In answer to Dr O. Hoffmann-Ostenhof's letter I would like to point out that the changes made by Index Chemicus in IUPAC nomenclature were limited to the use of unused or undefined letters, such as $J, O, U$ and $\mathrm{K}$. To the extent that these changes were not pointed out clearly, there may have been room for misunderstanding.

My article (Nature, 219, 1113; 1968) clearly stated, however, that IC-IUPAC notation is considered an openended system to which additions can be made as the need arises for effective computer storage and searching of long chain peptides. Indecd, the following additions have already been made:
A Cysteic acid
B $\beta$-Aminobutyric acid
C Homoserine
D Pyroglutaime
E $\beta$-Aminovaleric acid
F Sarcosine
G $\beta$-Alanine

The addition of these symbols, together with twenty other symbols for substituents, was prompted by their actual occurrence in the peptide literature which the Index Chemicus Registry System (ICRS) stores on computer tape. A significant and increasing percentage of the over 150,000 compounds encoded by ICRS each year involve peptides. To deal with such a large amount of new information, the IUPAC IUB system must be openended.

$$
\text { Yours faithfully, }
$$

Gabrielie S. Revesz

Institute for Scientific Information,

325 Chestnut Street,

Philadelphia, Pennsylvania 19106, USA.

\section{SI Units and Dimensionless Quantities}

SIR,--It is probably not generally realized that, because the electromagnetic SI units are associated with a rationalized system (Giorgi), the values of some dimensionless quantities, such as electric and magnetic susceptibilities, are $4 \pi$ times greater than in the (unrationalized) cgs systems. There is thus a real danger of errors in interpretation if it is wrongly assumed that for dimensionless quantities the units system adopted is irrelevant. So long as rationalized and unrationalized systems coexist it is important that in reporting such quantities the system used should be stated.

$$
\begin{aligned}
& \text { Yours faithfully, } \\
& \text { J. K. BECCONSALL }
\end{aligned}
$$

Imperial Chemical Industries, Limited,

Petrochemical and Polymer Laboratory.

\section{Policies for Pollution and its Cure}

Srr,--Your article on "Policies for Pollution and its Cure" (Nature, 222, 1013; 1969) is a timely reminder of the ineffectiveness of international legislation in controlling oil pollution. Oil pollution is, however, only one aspect of coastal pollution, but one which has great emotional impact. 'The use of the sea for the disposal of unwanted industrial waste material is an increasing threat to sea fisheries. Yet in Britain pollution of sea fisheries is controlled by the Sea Fisheries Act of 1888. In order to stop polluting discharges, the Sea Fisheries Officers have to "prove that pollution has occurred". This is, of course, exceedingly difficult to do because long term natural fluctuations in marine communities have been little studied. Thus the effect of the effluent can be put down to "natural fluctuations" in the community or species decimated.

Clearly Britain cannot alone strengthen her laws on effluent disposal and require home industries to control discharges if overseas competitors are not required to do 